Article

\title{
On the Effect of Filling Rate on Positive Macrosegregation Patterns in Large Size Cast Steel Ingots
}

\author{
Chunping Zhang ${ }^{1, * \mathbb{D}}$, Abdelhalim Loucif ${ }^{1}$, Mohammad Jahazi ${ }^{1, *}$, Rami Tremblay ${ }^{2}$ and \\ Louis-Philippe Lapierre ${ }^{2}$ \\ 1 Department of Mechanical Engineering, École de Technologie Supérieure, 1100 Notre-Dame Street West, \\ Montreal, QC H3C 1K3, Canada; Abdelhalim.Loucif@etsmtl.ca \\ 2 Finkl Steel-Sorel (Sorel Forge Co.), 100 Rue McCarthy, Saint-Joseph-de-Sorel, QC J3R 3M8, Canada; \\ rami.tremblay@gmail.com (R.T.); lplapierre@finkl.com (L.-P.L.) \\ * Correspondence: chunping.zhang.1@ens.etsmtl.ca (C.Z.); Mohammad.Jahazi@etsmtl.ca (M.J.); \\ Tel.: +1-514-396-8800-7868 (C.Z.); +1-514-396-8974 (M.J.)
}

Received: 13 September 2018; Accepted: 3 October 2018; Published: 11 October 2018

\begin{abstract}
The effect of filling velocity on positive macrosegregation in large size steel ingots was studied. Macrosegregation and macro/microstructures were characterized on the hot-tops and a portion of the upper section of two ingots. The measurements revealed that segregation features in the two ingots varied as a function of the alloying elements, and that the severity of positive macrosegregation in the casting body was reduced when the filling rate was increased. It was also found that at the higher filling rate, grain morphologies in the first solidified zones of the ingot changed from columnar to equiaxe, and secondary dendrite arm spacing (SDAS) became slightly smaller in the intermediate and final solidified zones. The experimental findings were analyzed in the framework of diffusion and convection-controlled solidification, as well as liquid metal flow theories. The solute dependence of segregation features was related to the difference in the solid-liquid partition coefficient and diffusion capability of each element in the liquid iron. Calculation of Reynolds numbers (Re) during the filling process, for both ingots, showed that higher filling velocity caused more instable movement of the liquid metal in the initial solidification stage, resulting in the modification of grain morphology, as well as accelerated solidification rate.
\end{abstract}

Keywords: medium-carbon low-alloy steel; large size ingot; hot-top; filling rate; positive macrosegregation

\section{Introduction}

Ingot casting is the only method for the production of large size mono-block high-strength steels used in the energy and transportation industries. Various forms of casting defects, however, may stem from the liquid metal filling stage, and then remain during the solidification process. Among them, macrosegregation, defined as chemical heterogeneity on the scale of the entire ingot, is one of the most important, particularly in high alloyed steels. Such compositional variation over large distances results in local changes in mechanical properties, which may lead to reduced ingot quality and sometimes even to ingot rejection [1,2]. While the severity of macrosegregation could be significantly reduced in small to medium size ingots through subsequent homogenization and forging operations; the situation is more complex when it comes to large size ingots. Therefore, a better understanding of macrosegregation mechanisms, with the aim to control its extent in heavy castings, is an important scientific challenge with direct industrial implications. This is particularly true when it comes to high value-added products, such as large size casting of high strength steels used for turbine shaft applications. 
Macrosegregation patterns in heavy low-alloy steel ingots is often characterized by intense positive segregation in the upper part, negative segregation at the bottom, and A- and V-shaped channel segregations in the body [3]. The pioneering work of Flemings et al., developed in the 1960s [4,5], set the theoretical bases for studying the mechanisms of macrosegregation. Since then, intensive research has been underway, and some critical process parameters have been identified and used as 'countermeasures' to produce sound ingots with improved quality and limited macrosegregation [6-9]. Specially, stringent control of the superheat [7], accelerating the solidification process in the mold [8], and improving ingot dimensions and configurations [9] have been investigated experimentally and numerically by researchers.

In recent years, the influence of filling process parameters has been studied by several researchers. Lee et al. [10] numerically studied the velocity, stress, and temperature fields of pure metal during mold filling and the solidification process, showing the important effect of the filling process on fluid flow and heat transfer at the early stages of the casting process. Im et al. [11] modeled the effects of wall temperature and filling flow on solidification, and pointed out that the residual flow due to the filling stage had an important effect on flow characteristics and the liquid metal solidified more slowly in higher flow situations. Ravindran et al. [12] presented a model to investigate the effect of mold filling on cold shuts formation and metal front migration, and incorporated inter-dendritic flow models to simulate the effect of solidification on the filling patterns and temperature fields. Yadav et al. [13] modeled the filling and solidification of a Pb-15 wt \% Sn alloy in a small side-cooled cavity $\left(50 \times 60 \mathrm{~mm}^{2}\right)$, and investigated melt superheat and filling velocity on the evolution of mushy regions and macrosegregation. It was found that residual flow due to filling effects significantly affected the shape of the mushy zone and delayed the development of solutal convection, resulting in less intense macrosegregation near the cold wall and a farther distance of A-segregates from the cold wall. Kermanpur et al. [14] simulated a 6-ton Cr-Mo low alloy steel to study the effect of bottom pouring rate and mold dimensions on solidification behavior and crack susceptibility during subsequent hot forging. Results showed that pouring the melt at a constant rate with a lower mold slenderness ratio would improve the riser efficiency and thereby possibly reduce crack susceptibility during subsequent hot forging. However, the effect of filling velocity on macrosegregation in large size steel ingots has not yet been reported, either numerically or experimentally.

In the present work, the effect of the filling rate on positive macrosegregation patterns in two large size cast ingots was studied. Various experimental techniques were used to examine the chemical composition, macro- and microstructure evolution of the hot-top and a portion of the upper section of the ingot. The results were analyzed in the framework of diffusion and convection controlled solidification, as well as liquid metal flow theories. The obtained results are expected to contribute to a better understanding of macrosegregation mechanisms in large size ingots. The results could also be used as an input data in numerical simulation codes which still suffer from lack of accurate determination of material characteristics [15].

\section{Materials and Experimental Process}

Two 40 metric ton (MT) cylindrical shape steel ingots, $250 \mathrm{~cm}$ in height and $150 \mathrm{~cm}$ in mean diameter, were cast in big-end-up cast iron molds using identical conditions, except for the filling rate. The hot-top, as an extension of the ingot that was $70 \mathrm{~cm}$ in height, was made in the mold lined inside with insulating tiles. During the production process, molten steel with the nominal composition listed in Table 1 was first produced by melting scrap material in an electric arc furnace, and then teemed into a ladle before ladle refining and vacuum degassing in an argon atmosphere. Then it was smoothly bottom poured into the mold at $1570{ }^{\circ} \mathrm{C}$, until the mold was filled to the top of the insulating tiles. Two filling times were used: the first ingot named LFR (Low Filling Rate ingot), with a filling rate of about $0.0018 \mathrm{~m} / \mathrm{s}$ (30 min for the $40 \mathrm{MT}$ ingot), and the second one, HFR (High Filling Rate ingot), with a filling rate of about $0.0024 \mathrm{~m} / \mathrm{s}(22 \mathrm{~min})$. The liquidus temperature for the current material was determined to be $1495^{\circ} \mathrm{C}$, using the thermodynamic software Thermo-Calc ${ }^{\circledR}$ (Thermo-Calc Software, 
Pittsburgh, PA, USA) [16]. Based on this value, the initial superheat (the excess temperature above the melting point) for both ingots was determined to be $75^{\circ} \mathrm{C}$.

Table 1. Nominal chemical composition of the investigated steel ingots, wt.\%.

\begin{tabular}{ccccccccc}
\hline $\mathbf{C}$ & $\mathbf{M n}$ & $\mathbf{C r}$ & $\mathbf{P}$ & $\mathbf{S}$ & $\mathbf{S i}$ & $\mathbf{N i}$ & $\mathbf{M o}$ & $\mathbf{F e}$ \\
\hline 0.36 & 0.85 & 1.82 & 0.01 & 0.0023 & 0.4 & 0.16 & 0.45 & balance \\
\hline
\end{tabular}

After solidification, a block comprised of the hot-top and $30 \mathrm{~cm}$ thick section of the ingot's main body was transversely cut off for investigation. Then, two plates $\left(130 \times 70 \times 1.5 \mathrm{~cm}^{3}\right)$ were sliced on each side of the axial plane. One slice was sectioned at regularly-spaced intervals into over 250 samples $\left(6.5 \times 4.5 \times 1.5 \mathrm{~cm}^{3}\right)$. All the faces in the centerline plane along the longitudinal axis were ground, and then chemically mapped using the Thermo Scientific the ARL ${ }^{\mathrm{TM}} 4460$ Optical Emission Spectrometer (Thermo Fisher Scientific Inc., Waltham, MA, USA). The axial face of the other slice was prepared by grinding and macroetched in a $50 \% \mathrm{HCl}$ solution at $50{ }^{\circ} \mathrm{C}$ to reveal macrosegregation patterns. Some selected regions were metallographically prepared and etched in Oberhoffer's etchant, and then optically observed using a binocular microscope.

It should be noted that hot-tops are commonly used in the ingot casting industry in order to provide a reservoir of molten steel for feeding the shrinkage zone as the ingot solidifies [1]. They are generally cut off from the ingot body after solidification. However, there is a growing interest in reserving at least part of the hot-top for further use [17]. Thus, in the present study, positive segregation in the hot-top was also characterized, along with the upper section of the casting body, to evaluate and validate such possibility. It is clear that, if successful, the findings could result in significant material and energy saving in the ingot casting industry.

The chemical composition of each specimen was obtained by averaging out 3 random spectrometer measurements and calculated using the relation [18]:

$$
R_{i}=\left(\omega_{i}-\omega_{0, i}\right) / \omega_{0, i}
$$

Here, $R_{i}$ is the segregation ratio for solute element $i, \omega_{i}$ is the solute's local concentration and $\omega_{0, i}$ is its nominal concentration value. A positive $R_{i}$ value corresponds to positive segregation, and conversely, a negative $R_{i}$ to negative segregation. Segregation ratio patterns of different elements in the longitudinal section of the entire block were then reconstructed using MATLAB ${ }^{\circledR}$ (The MathWorks Inc., Natick, MA, USA) [19] by filling the areas between the isolines using constant colors corresponding to the local segregation intensities.

\section{Results and Discussions}

\subsection{General Macrosegregation Patterns}

The chemical distribution patterns of the principal alloying elements on the axial plane in the two ingots are shown in Figure 1. The observed section is illustrated in grey in the upper right corner of the figure. The patterns on the left are for LFR and those on the right are for HFR. Regions with no segregation $\left(R_{i}=0\right)$ are colored with light blue, negative segregation $\left(R_{i}<0\right)$ with dark blue, and the hot-top/casting body separation position is marked with a black dashed line. It can be seen that all the solute segregation ratio maps appear symmetric about the ingot central axis, even though minor differences are present. A gradient in solute concentration is observed over the ingot's radius from the periphery to the center and from the lower to the upper region. This indicates that the slow rise in concentration of solute in the solid was the result of bulk liquid becoming progressively concentrated in solute elements. 

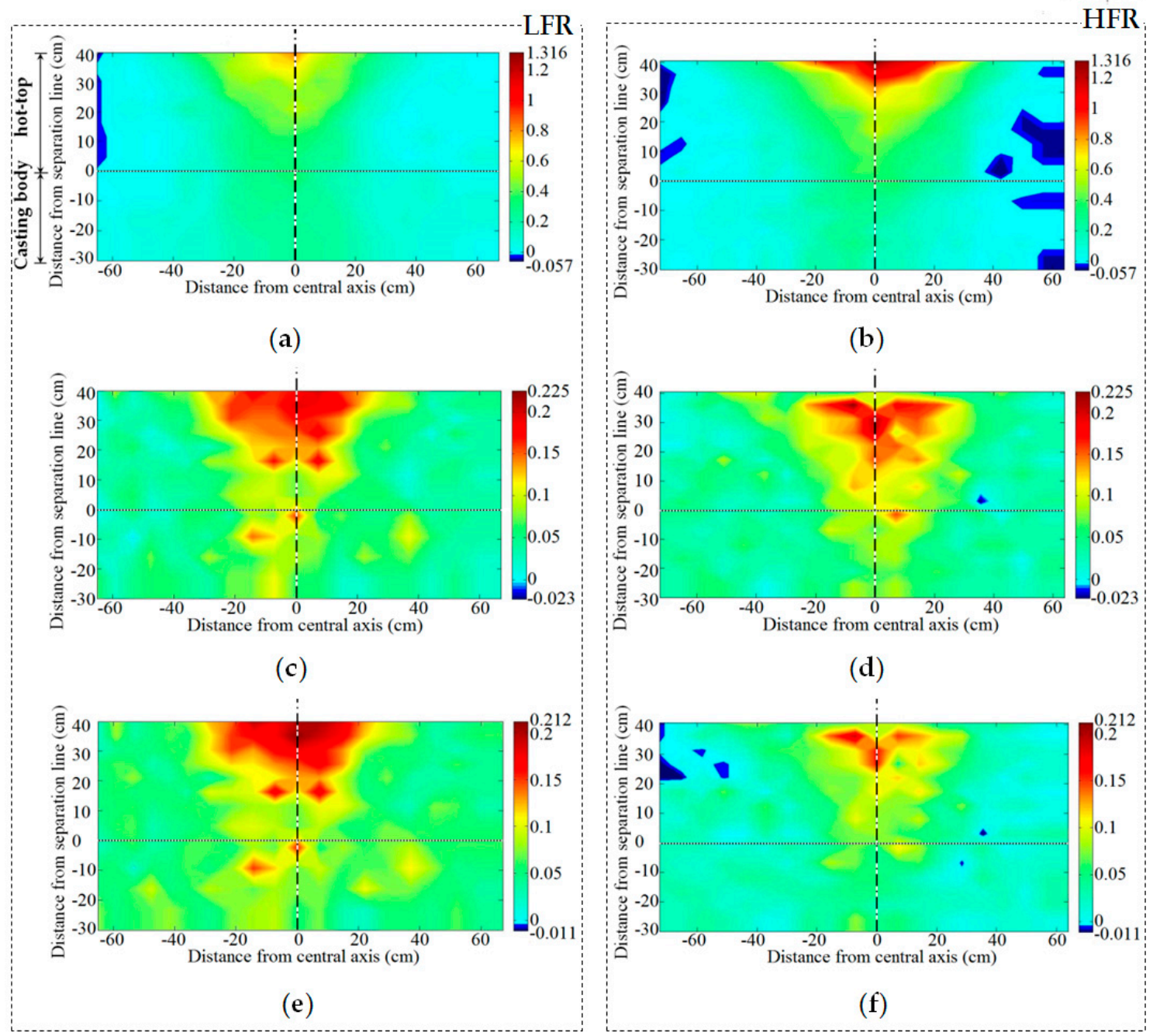

Figure 1. Segregation ratio patterns in the two ingots (LFR (Low Filling Rate ingot) and HFR (High Filling Rate ingot)) for the three analyzed solutes: (a,b) C; (c,d) Mn; (e,f) Cr.

A weak difference from nominal composition (negative segregation) is observed in the region next to the surface layer of the hot-tops. This difference could be attributed to the increased local solidification time due to the presence of the refractory lining in the hot-top wall. The presence of the refractory lining decreases the cooling rate, as compared to the mold wall, and therefore reduces the segregation in these regions [18]. On top of this, some concentration islands were observed, which can be associated with possible segregation channels.

It is also noted in Figure 1 that segregation features in the two ingots were found to vary as a function of alloying elements. Carbon is the element with the highest segregation ratio. The most intense positive segregation ratio of carbon, manganese, and chromium in both ingots was found to be sequenced in decreasing order, and reached $1.316,0.225$, and 0.212 , respectively. The above sequence is consistent with the descending order of the solid-liquid partition coefficient $k$ (the ratio of the solute content in the solid $C_{S}$ compared to the solute content in the liquid $C_{L}$ in equilibrium, $k=C_{S} / C_{L}$ ) of each solute. This coefficient was determined for each element based on linearized binary phase diagrams, with respect to iron calculated using Thermo-Calc ${ }^{\circledR}$ (Thermo-Calc Software, Pittsburgh, PA, USA) [16], and the results are shown in Figure 2a. The smaller the partition coefficient of a solute element, the more solute the solid will reject into the liquid during solidification, and the more intense 
the resulting segregation will be [20]. Although the $k$ value of manganese lies between carbon and chromium, as seen in Figure 2a, its slightly lower diffusion coefficient in the liquid iron (as displayed in Figure $2 b$ [21]) results in a similar positive segregation pattern to chromium. In addition, as shown in Figure 1, the most intense segregations of all the solutes (the red color in the maps) in LFR were observed at the top center of the hot-top, in contrast to the lower locations of positive segregates of manganese and chromium in HFR.

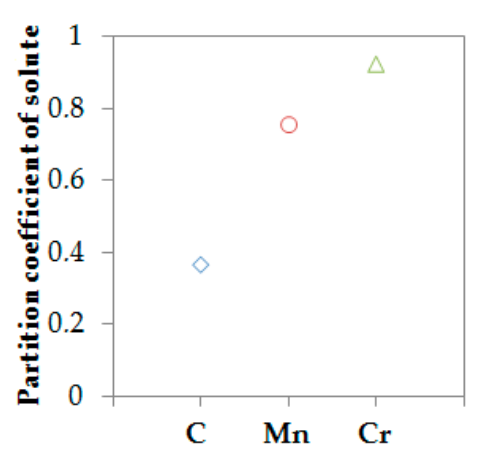

(a)

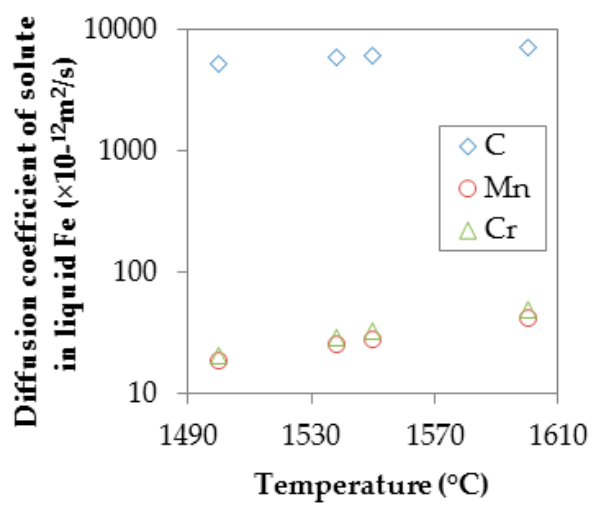

(b)

Figure 2. (a) Partition coefficients of different alloying elements determined based on linearized binary phase diagrams with respect to iron; (b) Evolution of diffusion coefficients of solutes in liquid iron as a function of temperature.

\subsection{Effect of Filling Rate on Segregation Severity}

Frequency distribution of segregation ratios were examined in the hot-top and the upper section of the casting body for the two investigated ingots. The results are plotted in histograms in Figure 3 . It can be seen in Figure 3a that in the hot-top of ingot HFR, the intensity of positive segregation of all the analyzed elements is more pronounced (histograms with $R_{i}>0$ ), especially in higher segregation regions $\left(R_{i}>0.1\right)$; solute concentrations close to the nominal composition are less pronounced (histograms in the region $R_{i}=0$ ). In contrast, in the upper section of the casting body of ingot HFR (Figure $3 \mathrm{~b}$ ), the positive segregation is less intense (histograms with $R_{i}>0$ ) and more solutes are present with concentrations near the nominal composition $\left(R_{i}=0\right)$.

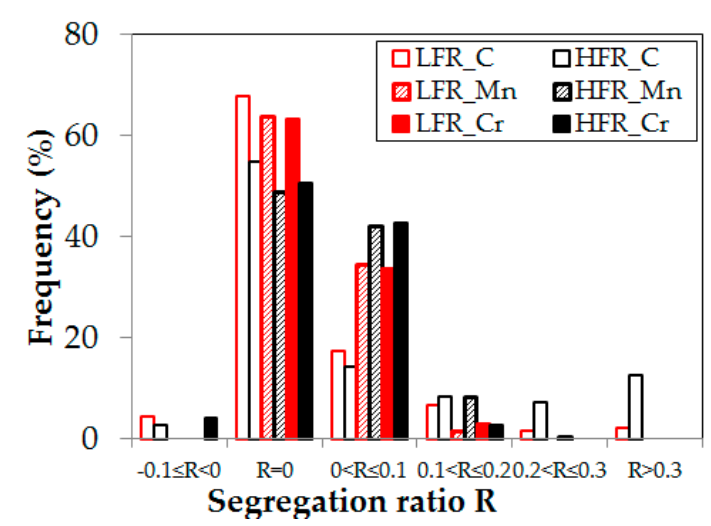

(a)

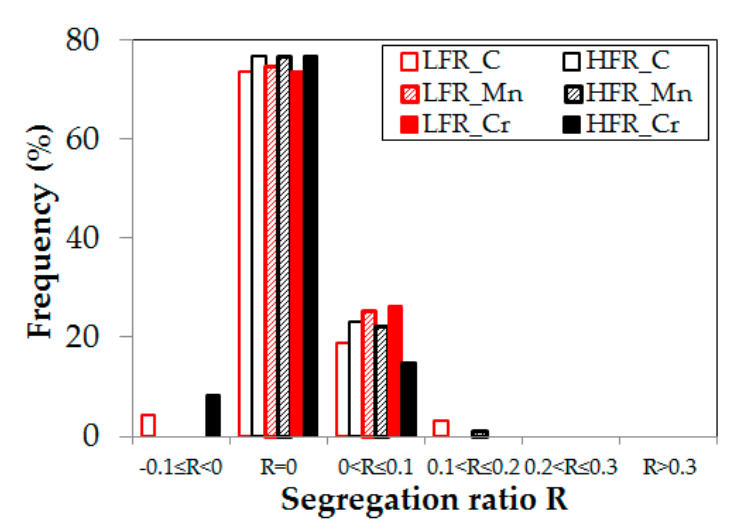

(b)

Figure 3. Frequency distribution of segregation ratios: (a) In the hot-top; (b) In the upper section of ingot body.

The above-mentioned tendency, more severe segregation in the hot-top of HFR and less severe segregation in the casting body of HFR, was more remarkable when the evolution of carbon and manganese was examined along the central axis, as shown in Figure $4 \mathrm{a}, \mathrm{b}$. The axial concentration 
examination of chromium presented less severe segregation in both the casting body and the hot-top of HFR, as shown in Figure 4c. Moreover, it can be seen that in both ingots, the axial concentrations of carbon present a stepped monotonic increase from the cutting section to the top center of the hot-top. In contrast, positive segregation of manganese and chromium were found to increase progressively in a fluctuating way. The fluctuation was more distinct in HFR. The most intense positive segregation regions of manganese and chromium in HFR were found to lie about $5 \mathrm{~cm}$ below the corresponding regions in the low filling rate case, LFR.

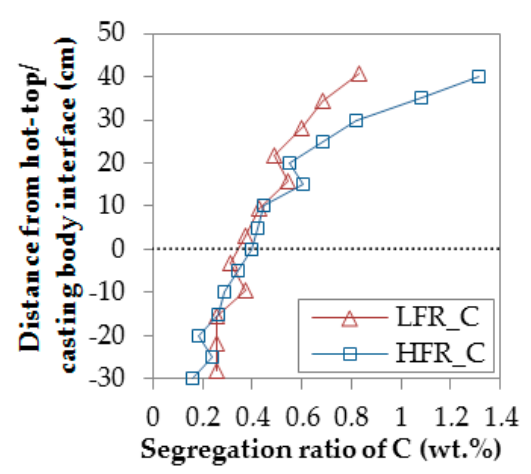

(a)

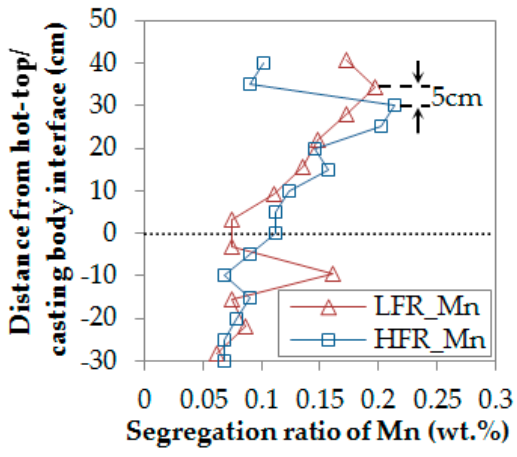

(b)

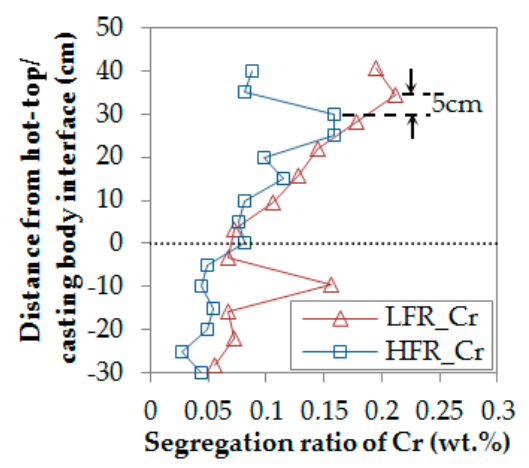

(c)

Figure 4. Segregation ratio profiles along the ingot central axis of the two ingots: (a) carbon; (b) manganese; (c) chromium.

An examination of the concentration distribution along the cutting line of the two ingots (i.e., $30 \mathrm{~cm}$ below the hot-top/casting body interface), as shown in Figure 5, revealed that the concentration profiles of all the three solutes in the casting body of HFR are below the LFR case and closer to the nominal composition $\left(R_{i}=0\right)$, presenting less severe segregation.

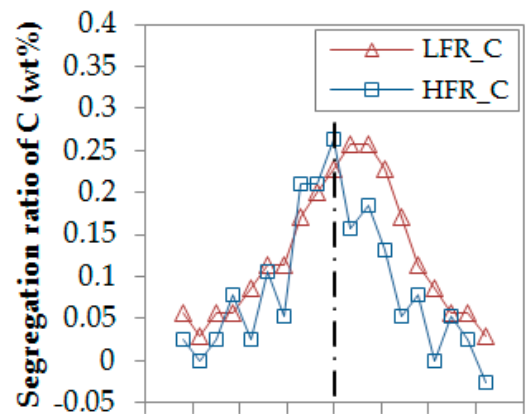

$-80-60-40-20 \quad 0 \quad 20 \quad 40 \quad 60 \quad 80$

Distance from ingot central axis $(\mathrm{cm})$

(a)

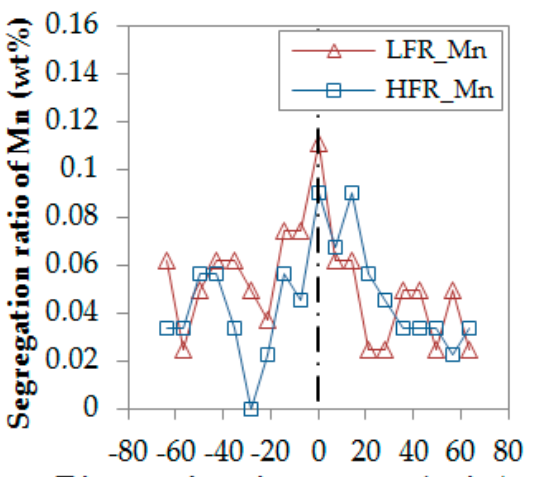

Distance from ingot central axis $(\mathrm{cm})$

(b)

Figure 5. Cont. 


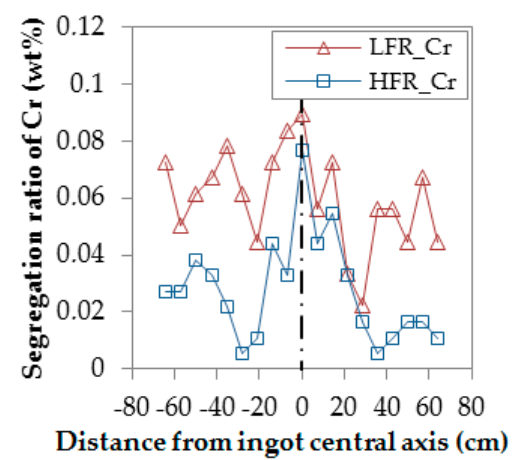

(c)

Figure 5. Segregation ratio profiles along the bottom of the cutting section of the two ingots: (a) carbon; (b) manganese; (c) chromium.

The above results indicate that the filling velocity has a clear influence on the resultant macrosegregation, at least in the studied zones, of large size ingots. The obtained results confirm the observations of Yadav et al. [13] in small size ingots, despite the fact that in large size ingots the filling time is very short compared to the total solidification time.

\subsection{Effect of Filling Rate on Fluid Flow and Solidification Time}

Considering the large size of the ingots, the solid percentage formed at the end of filling was not expected to induce changes in the melt density, temperature, and viscosity. Thus, the influence of filling velocity on the flows of the liquid steel during the filling stage (considered as isothermal flow of a single phase material) was analyzed using the dimensionless Reynolds number (Re) [22,23]. The proposed approach is similar to the ones used by Marx et al. [22] and Wu et al. [24] for physical modelling of liquid melt flow in steel ingots:

$$
\operatorname{Re}=\frac{\rho v d}{\mu}
$$

In the above equation, $\rho$ represents the density of the fluid $\left(\mathrm{kg} / \mathrm{m}^{3}\right), v$ the fluid flow velocity $(\mathrm{m} / \mathrm{s}), d$ the characteristic length $(\mathrm{m})$, and $\mu$ the dynamic viscosity of the fluid (Pa.s).

The density and the dynamic viscosity of the investigated steel at the filling temperature, $1570{ }^{\circ} \mathrm{C}$, were determined using Thermo-Calc ${ }^{\circledR}$ (Thermo-Calc Software, Pittsburgh, PA, USA) [16] and JMatPro ${ }^{\circledR}$ (Sente Software Ltd., Guildford, Surrey, UK) [25], respectively. The mean filling speed was taken as the characteristic velocity and the average diameter of the cylinder mold cavity as characteristic length. After calculation with all the determined parameters, Reynolds numbers of 3208 for LFR and 4375 for HFR during the pouring process were obtained. The higher value of $\mathrm{Re}_{\mathrm{HFR}}$ indicates that more flow instabilities and movements were produced inside the mold under HFR condition. This flow instability is expected to result in some residual flow up to the initial stage of solidification under HFR condition.

Macroetch analysis of the zones near the surface of the ingot (first solidified zones), as reported in Figure 6, revealed columnar grains in the casting body of LFR (Figure 6a) and equiaxed grains in the same position of HFR (Figure $6 \mathrm{~b}$ ). The examined region is encircled in red in the upper right corner of Figure 6. A schematic views of the grain morphologies are also provided for clarification (due to the large size of the blocks and the grains, it is difficult to capture high quality images with uniform light and shade in one single picture). Campbell [26] found that a dampened fluid flow promotes columnar growth, while an unsteady liquid movement promotes the development of equiaxed grain structure [27]. The presence of the equiaxed grain morphology in the first solidified zone in HFR is probably indicative of the presence of higher liquid instabilities at the start of solidification, as also predicted by the Reynolds number calculations. 

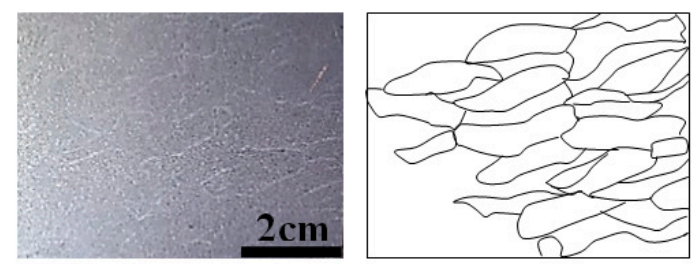

(a)

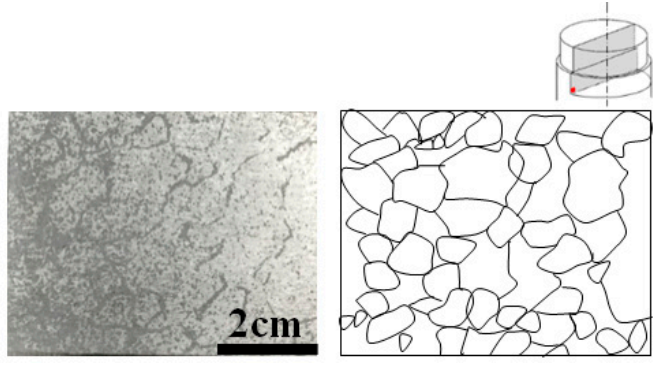

(b)

Figure 6. Grain morphologies in the bordering zones (the chill walls are on the left) of (a) LFR; (b) HFR.

Several researchers have examined the mutual influence of residual flow and solidification on the thermal and solutal behaviors of the ingot. Zhao et al. [28] and Zhu et al. [29] reported that the presence of residual flow can homogenize the temperature and solute field in the bulk liquid at the early stages of solidification, while Wang et al. [30,31] and Aboutalebi [32] related it to a decrease of temperature gradient in the pool of liquid. The lower temperature gradient can prolong the thermal convection time in the cavity, and delay the development of solutal convection [33], because of better mixing of solute ahead of the liquidus front and thus decreased density gradients [34]. Others reported that delayed solutal convection can significantly affect the distribution of solutes [35-37], and hence affect the evolution of macrosegregation patterns during the intermediate and final stages of solidification. Therefore, more intense movement of the liquid metal in the initial solidification stage, caused by higher filling velocity, is probably the source for the observed reduced solute segregation in the casting body in the HFR ingot as compared to LFR.

In addition, secondary dendrite arm spacing (SDAS) measurements along the cutting section of the LFR ingot revealed SDAS values as large as $536 \mu \mathrm{m}$ in the $1 / 2$ radius position from the center and $474 \mu \mathrm{m}$ in the ingot center. The two observed regions solidified in the intermediate or final stage of the solidification process. The SDAS values were also in the same range for the HFR ingot but slightly smaller (530 $\mu \mathrm{m}$ and $470 \mu \mathrm{m}$, respectively, in the corresponding regions), as presented in Figure 7 . Lower SDAS values are generally correlated with shorter solidification times [26]. Furthermore, as reported by Vives et al. [35], higher filling rates result in increased dissipation rate of the melt superheat with the mold and accelerated solidification rate due to the higher strength of convection. Therefore, the findings of the shorter solidification time resulting from higher filling velocity could result in less time available for solutes to transport, and could be another source for the lower segregation intensity in the casting body of HFR. It should be noted that further experimental work on measuring the SDAS values in different locations of the ingots will contribute to confirm and better quantify the differences in the SDAS values for each condition.

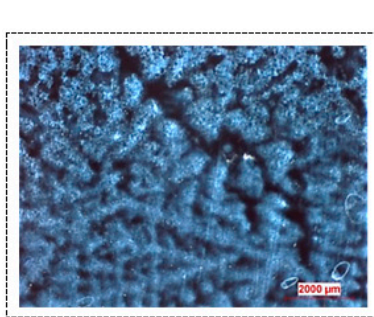

(a)

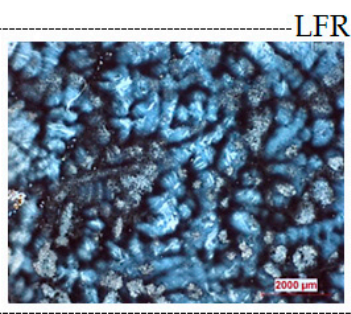

(b)

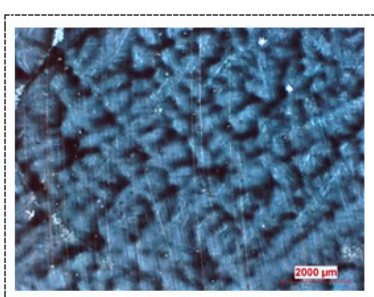

(c)

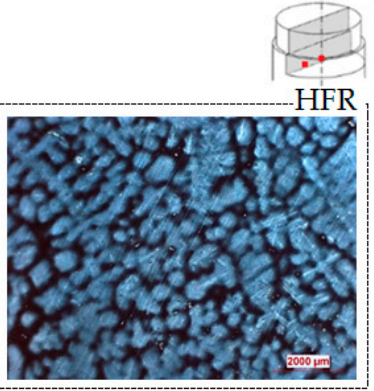

(d)

Figure 7. Micrographs along the bottom of the cutting section $(30 \mathrm{~cm}$ below the hot-top/casting body separation position) of ingots LFR (left) and HFR (right): (a,c) In the 1/2 radius position from the center; $(\mathbf{b}, \mathrm{d})$ In the center. 
The shorter solidification time and the lower diffusion coefficient of the solutes are probably the main sources for the observed lower location $(\sim 5 \mathrm{~cm})$ of the positive manganese and chromium concentration cores in HFR (as reported in Figures 1 and 4). Besides, no sufficient diffusion time could be the origin for the observed higher fluctuations in the concentrations of manganese and chromium in the radial and axial distributions in HFR (as seen in Figures 4 and 5). The reduced segregation in the casting body of HFR, produced under fast filling conditions, is probably the root cause for the higher segregation intensity observed in the hot-top of HFR. Indeed, a lower segregation level in the casting body results in more partitioning of solutes into the melt and their accumulation towards the end of solidification in the upper part of the hot-top [4]. The axial less severe segregation of chromium in both the casting body and the hot-top of HFR could be due to less available time for the diffusion of the solute.

\section{Conclusions}

The effect of filling rate on positive macrosegregation characteristics in large size steel ingots was studied based on the analysis of the hot-top and a small portion of the main ingot body. The following conclusions can be drawn:

1. General macrosegregation patterns presented the solute dependence of segregation features, which was related to the difference in the solid-liquid partition coefficient and diffusion capability of each element in the liquid iron.

2. Frequency distribution of segregation ratios, as well as the axial and horizontal concentration evolutions, presented less severe segregation in the casting body of the ingot with the higher filling rate.

3. One source of the reduced solute segregation in the casting body in the higher filling rate case is the presence of higher liquid instabilities at the start of solidification, which was predicted by the Reynolds number calculations during the filling process, and confirmed by macroetch grain morphology observations in the first solidified zones.

4. Another source for the lower segregation intensity in the casting body of higher filling rate case is the shorter solidification time, resulting in less time available for solutes to transport, which was revealed by the SDAS measurements along the cutting section of the ingot in the regions solidified in the intermediate and final stages of the solidification process.

Therefore, the alleviation of solute segregation in the upper section of the casting body resulting from the accelerated filling process could be due to a combination of the more intense movement of the liquid metal, caused by higher kinetic energy of the liquid metal in the initial solidification stage, and shorter solidification time that reduces the available time for the segregation to build up.

Author Contributions: Conceptualization, M.J. and C.Z.; Methodology, C.Z.; Software, C.Z. and A.L.; Validation, C.Z.; Formal Analysis, C.Z.; Investigation, C.Z. and R.T.; Resources, R.T., M.J. and L.-P.L.; Data Curation, C.Z.; Writing-Original Draft Preparation, C.Z; Writing-Review \& Editing, M.J. and A.L.; Visualization, C.Z.; Supervision, M.J.; Project Administration, M.J.; Funding Acquisition, M.J.

Acknowledgments: The financial support from the Natural Sciences and Engineering Research Council (NSERC) of Canada in the form of a Collaborative Research and Development Grant (CRDG) under number 470174 is gratefully acknowledged. Finkl Steel-Sorel Co. for providing the material is greatly appreciated.

Conflicts of Interest: The authors declare no conflict of interest.

\section{References}

1. Majka, T.F.; Matlock, D.K.; Krauss, G. Development of microstructural banding in low-alloy steel with simulated Mn segregation. Metall. Mater. Trans. A 2002, 33A, 1627-1637. [CrossRef]

2. Loucif, A.; Fredj, E.B.; Harris, N.; Shahriari, D.; Jahazi, M.; Lapierre-Boire, L.P. Evolution of A-type macrosegregation in large size steel ingot after multistep forging and heat Treatment. Metall. Mater. Trans. $B$ 2018, 49B, 1046-1055. [CrossRef] 
3. Pickering, E.J.; Chesman, C.; Al-Bermani, S.; Holland, M.; Davies, P.; Talamantes-Silva, J. A comprehensive case study of macrosegregation in a steel ingot. Metall. Mater. Trans. B 2015, 46B, 1860-1874. [CrossRef]

4. Flemings, M.C. Our understanding of macrosegregation: Past and present. ISIJ Int. 2000, 40, 833-841. [CrossRef]

5. Beckermann, C. Modeling of macrosegregation: Applications and future needs. Int. Mater. Rev. 2002, 47, 243-261. [CrossRef]

6. Combeau, H.; Založnik, M.; Hans, S.; Richy, P.E. Prediction of macrosegregation in steel ingots: Influence of the motion and the morphology of equiaxed grains. Metall. Mater. Trans. B 2009, 40B, 289-304. [CrossRef]

7. Pikkarainen, T.; Vuorenmaa, V.; Rentola, I.; Leinonen, M.; Porter, D. Effect of superheat on macrostructure and macrosegregation in continuous cast low-alloy steel slabs. IOP Conf. Ser. Mater. Sci. Eng. 2016, 117, 1-7. [CrossRef]

8. Galkin, A.N.; Zyuban, N.A.; Rutskii, D.V.; Gamanyuk, S.B.; Puzikov, A.Y.; Firsenko, V.V. Effect of chilling of the top part of a steel ingot on the conditions of its crystallization and the quality of forgings obtained from it. Metallurgist 2013, 57, 199-206. [CrossRef]

9. Dub, V.S.; Romashkin, A.N.; Mal'ginov, A.N.; Ivanov, I.A.; Tolstykh, D.S. Effect of the geometry of an ingot on its chemical heterogeneity. Part I. Metallurgist 2014, 57, 987-995. [CrossRef]

10. Lee, J.; Mok, J.; Hong, C.P. Straightforward numerical analysis of casting process rectangular mold: From filling to solidification. ISIJ Int. 1999, 39, 1252-1261. [CrossRef]

11. Im, I.T.; Kim, W.S.; Lee, K.S. A unified analysis of filling and solidification in casting with natural convection. Int. J. Heat Mass Transf. 2001, 44, 1507-1515. [CrossRef]

12. Ravindran, K.; Lewis, R.W. Finite element modelling of solidification effects in mould filling. Finite Elem. Anal. Des. 1998, 31, 99-116. [CrossRef]

13. Yadav, A.; Pathak, N.; Kumar, A.; Dutta, P.; Sarkar, S. Effects of the filling process on the evolution of the mushy zone and macrosegregation in alloy casting. Model. Simul. Mater. Sci. 2009, 17, 1-19. [CrossRef]

14. Kermanpur, A.; Eskandari, M.; Purmohamad, H.; Soltani, M.A.; Shateri, R. Influence of mould design on the solidification of heavy forging ingots of low alloy steels by numerical simulation. Mater. Des. 2010, 31, 1096-1104. [CrossRef]

15. Pickering, E.J. Macrosegregation in steel ingots: The applicability of modelling and characterisation techniques. ISIJ Int. 2013, 53, 935-949. [CrossRef]

16. Andersson, J.O.; Helander, T.; Höglund, L.; Shi, P.F.; Sundman, B. THERMO-CALC \& DICTRA, computational tools for materials science. Calphad 2002, 26, 273-312. [CrossRef]

17. Qian, S.; Hu, X.; Cao, Y.; Kang, X.; Li, D. Hot top design and its influence on feeder channel segregates in 100-ton steel ingots. Mater. Des. 2015, 87, 205-214. [CrossRef]

18. Duan, Z.; Tu, W.; Shen, B.; Shen, H.; Liu, B. Experimental measurements for numerical simulation of macrosegregation in a 36-ton steel ingots. Metall. Mater. Trans. A 2016, 47A, 3597-3605. [CrossRef]

19. MATLAB and Statistics Toolbox Release 2012b; The MathWorks, Inc.: Natick, MA, USA, 2012.

20. Schneider, M.C.; Beckermann, C. Formation of macrosegregation by multicomponent thermosolutal convection during the solidification of steel. Metall. Mater. Trans. A 1995, 26A, 2373-2388. [CrossRef]

21. Miettinen, J. Calculation of solidification-related thermophysical properties for steels. Metall. Mater. Trans. $B$ 1997, 28B, 281-297. [CrossRef]

22. Marx, K.; Rödl, S.; Schramhauser, S.; Seemann, M. Optimization of the filling and solidification of large ingots. In Proceedings of the 2nd International Conference Ingot Casting Rolling \& Forging ICRF, Milan, Italy, 7-9 May 2014; Volume 11-12, pp. 11-19.

23. Reikher, A.; Barkhudarov, M.R. Casting: An Analytical Approach-Engineering Materials and Processes; Verlag London Ltd.: London, UK, 2007; pp. 23-25, ISBN 978-1-84628-850-0.

24. Wu, M.; Vakhrushev, A.; Nummer, G.; Pfeiler, C.; Kharicha, A.; Ludwig, A. Importance of melt flow in solidifying mushy zone. Open Transp. Phenom. J. 2010, 2, 16-23. [CrossRef]

25. JMatPro User's Guide; Sente Software Ltd.: 2005. Available online: https://manualzz.com/doc/4150587/ jmatpro-user-s-guide (accessed on 8 October 2018).

26. Campbell, J. Complete Casting Handbook-Metal Casting Processes, Metallurgy, Techniques and Design, 1st ed.; Butterworth-Heinemann: Waltham, MA, USA, 2011; pp. 119-269, ISBN 9781856178099.

27. Willers, B.; Eckert, S.; Michel, U.; Haase, I.; Zouhar, G. The columnar-to-equiaxed transition in Pb-Sn alloys affected by electromagnetically driven convection. Mat. Sci. Eng. A 2005, 402, 55-65. [CrossRef] 
28. Zhao, Z.; Cui, J.; Dong, J.; Zhang, B. Effect of low-frequency magnetic field on microstructures and macrosegregation of horizontal direct chill casting 7075 aluminum alloy. J. Mater. Process. Technol. 2007, 182, 185-190. [CrossRef]

29. Zhu, Q.F.; Zhao, Z.H.; Cui, J.Z.; Zuo, Y.B.; Wang, X.J. Effect of combined application of electromagnetic fields on horizontal direct chill casting of 7050 aluminium alloy. Mater. Sci. Technol. 2008, 24, 560-566. [CrossRef]

30. Wang, X.; Ma, N.; Bliss, D.F.; Isele, G.W.; Becla, P. Combining static and rotating magnetic fields during modified vertical bridgman crystal growth. J. Thermophys. Heat Transf. 2007, 21, 736-743. [CrossRef]

31. Wang, B.; Yang, Y.; Tang, W. Microstructure refinement of AZ91D alloy solidified with pulsed magnetic field. Trans. Nonferrous Met. Soc. China 2008, 18, 536-540. [CrossRef]

32. Aboutalebi, M.R. Modelling of Turbulent Transport Phenomena and Solidification in Continuous Casting Systems. Ph.D. Thesis, Department of Mining and Metallurgical Engineering, McGill University, Montreal, QC, Canada, February 1994.

33. Liu, D.R.; Kang, X.H.; Fu, P.X.; Li, D.Z. Modeling of macrosegregation in steel ingot: Influence of mold shape and melt superheat. Kovove Mater. 2011, 49, 143-153. [CrossRef]

34. Zhang, C.; Bao, Y.; Wang, M. Influence of casting parameters on shrinkage porosity of a 19 ton steel ingot. Metall. Ital. 2016, 1, 37-44.

35. Vives, C.; Perry, C. Effects of electromagnetic stirring during the controlled solidification of tin. Intl. J. Heat Mass Transf. 1986, 29, 21-33. [CrossRef]

36. Hachani, L.; Saadi, B.; Wang, X.D.; Nouri, A.; Zaidat, K. Experimental analysis of the solidification of Sn-3 wt .\% Pb alloy under natural convection. Intl. J. Heat Mass Transf. 2012, 55, 1986-1996. [CrossRef]

37. Liu, S.F.; Liu, L.Y.; Kang, L.G. Refinement role of electromagnetic stirring and strontium in AZ91 magnesium alloy. J. Alloys Compd. 2008, 450, 546-550. [CrossRef]

(C) 2018 by the authors. Licensee MDPI, Basel, Switzerland. This article is an open access article distributed under the terms and conditions of the Creative Commons Attribution (CC BY) license (http:/ / creativecommons.org/licenses/by/4.0/). 